\title{
Incursões e diálogos pelo berço do humano (ou sobre quando a arquitetura liberta a cidade)
} DANIEL CORSI ${ }^{I}$

\begin{abstract}
Estranho, a esta terra chegas da qual perguntas, e varões desmedidos e iníquos a dominam. Premiaste-o com presentes, miríades ofertando, estéreis; se o tivesses alcançado, vivo, na cidade de Ítaca, então ele te enviaria de volta, retribuindo com belos dons e nobre hospedagem: essa é a norma para quem inicia.
\end{abstract}

(Homero, 2014, p.594)

I NDAGO-ME para que se indaguem todos: sobre qual noção de respeito estruturamos nossa civilização? Dentro das batalhas travadas entre deuses e deuses, entre deuses e humanos, entre humanos e humanos, alguma norma pode ser capaz de revelar um mínimo grau de altruísmo em seus atos? Eis que, mais do que nunca, o conflito nos define. No entanto, é só o que nos resta a petrificação dessa condição? É só o que nos resta a perpetuação desse estado fatal?

\section{Incursão 1 (Estado de sítio)}

Nossos valores ocidentais foram inaugurados na literatura por meio da narrativa daquele que podemos reconhecer como um de nossos confrontos mais extremos: a sobrevivência humana frente ao poder divino. Dentre as incontáveis contribuições do poema de Homero - escrito no século VIII a.C. - ao nosso pensamento, encontra-se o caráter das relações humanas descritas ao longo de seus versos, como esses que revelam o primeiro contato de um pai que dialoga com o filho desaparecido há muito tempo. Retornando à sua tão cara urbe após uma interminável odisseia, Odisseu - ou Ulisses - ouve de Laerte palavras que o colocam diante da norma fundamental presente na maioria de seus diálogos: a hospitalidade.

Evidente que, naquele momento, as urbes não nascem sem instaurar fronteiras e conflitos, mas a hospitalidade enfatizada por Homero apresenta justamente o estrangeiro, o estranho - e porque não "o diferente" - segundo uma noção de respeito cuja presença basal no poema deveria se ver ainda preservada na estrutura ética de nossa civilização. No entanto, além da beleza épica da história, o que reconhecemos é a extinção dessa reciprocidade amistosa através de nossas eras e uma saga que nos legou predominantemente a metáfora elementar da violência de nossa sobrevivência. 
Vivemos tempos sombrios e conduzidos por realidades cada vez mais extremas. As concentrações humanas presenciadas atualmente assumem proporções que evidenciam sua condição insustentável. Com $54 \%$ da população mundial vivendo em áreas urbanas, ${ }^{1}$ podemos dizer que a cidade contemporânea - a metrópole global - é o registro fiel da precariedade de nossas instituições. Vivemos num estado de conflito em que, espantosamente, a hospitalidade original figura entre as normas menos presentes entre nós.

Estamos perante os cenários alarmantes das "cidades de muros" (Caldeira, 2000) que seguimos erguendo. Diante delas, podemos admitir alguns desdobramentos: nos enfrentamos numa guerra global, nos isolamos definitivamente em fortalezas solitárias ou nos abandonamos num êxodo urbano sem rumo. É essa condição sitiada que vemos imperar nas estruturas sociais, políticas e econômicas que conduzem o desenvolvimento das cidades e, consequentemente, da arquitetura. Contudo, é imprescindível a consciência de que cada um desses fatos é parte do andamento inexorável de nossa existência e, como registro de grande parte dos atos de nossa espécie, a cidade é um acontecimento humano igualmente inevitável.

Da utopia espessa da modernidade à liberdade volátil da pós-modernidade, assistimos ao século XX nos levar do sonho à nostalgia rumo a uma ausência significativa de sentido: encontramo-nos num cenário ruidoso, preenchido pela postura beligerante de nossos agentes contemporâneos aos quais as cidades estão submetidas e, novamente, também a arquitetura.

Portanto, dentre as diversas maneiras de nos posicionarmos frente a essa realidade, é necessário que as normas predominantes que vêm conduzindo as relações indissociáveis entre arquitetura e cidade sejam devidamente identificadas. Tarefa complexa, mas que nos permite constatar a emergência da superação da desigualdade, do medo e do conflito que cada vez mais assolam a nossa convivência.

\section{Incursão 2 (O arquiteto-general)}

Ação, campo, cartografia, estratégia, intervenção, malha, operação, plano, tática, território. É revelador que nas últimas décadas palavras como essas tenham tomado conta do vocabulário cotidiano da arquitetura. Relacionadas à linguagem bélica, é como se arquitetos e urbanistas tivessem se tornado generais - ou soldados rasos - de um campo de batalha urbano cuja autodefesa parece ser a única missão possível. Conforme apontado pelo arquiteto espanhol Rafael Moneo, esse é um sintoma que revela a maneira como passamos a lidar com a cidade, princípio e destino de nossas ações:

Não há dúvida de que associar "estratégia" à guerra, com a gestão de operações militares, é a primeira interpretação do termo [...]. Portanto, o projeto é entendido como um campo de batalhas onde um avança tentando antecipar o que o futuro trará ou como outros se moverão. Uma obra de arquitetura não é mais o resultado da concepção da estrutura de algo como um objeto, mas a disposição de uma série de volumes em uma ma- 
lha, disponível para ser ocupada independentemente de seus possíveis usos futuros. Assim como o marechal de campo observa um campo de batalha e cuidadosamente explora e examina os arredores para determinar como irá implantar suas tropas, o arquiteto agora examina o território onde os edifícios projetados serão erguidos. (Moneo, 2010, p.227) ${ }^{2}$

Além das superestruturas de nossa sociedade - vinculadas aos poderes políticos, econômicos e culturais - a vulnerabilidade das normas, a escassez de critérios, a fragilidade dos objetivos e a imprevisibilidade dos interesses também colaboraram para que emergisse nesses profissionais, supostos proponentes do futuro, um posicionamento reativo frente aos riscos fazerem parte deste dinamismo radical.

Diferente de um arquiteto fundamentalmente propositivo, Moneo nos coloca diante de um arquiteto reativo que, para assegurar a mínima vigência de suas ideias, vem demonstrando a necessidade de se armar de ferramentas conceituais consideravelmente distantes dos princípios e das poéticas fundamentais da arquitetura. De grande parte das realizações arquitetônicas que hoje participam da construção das cidades foram subtraídas as capacidades de refletir e comunicar, para encontrar na ação e na reação seus maiores objetivos: "Como resultado de tal endeusamento da ação, a cena arquitetônica se converteu em algo diferente, inclusive, atrever-me-ia a dizer, em algo que renuncia conscientemente aos

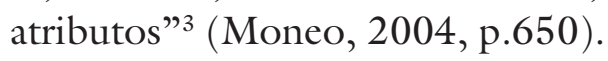

É importante reconhecer a necessidade disso para a emergencial superação das contradições e desequilíbrios atuais. De fato, há poderes e forças que somente por meio de uma abordagem combativa podem ser enfrentados. Por outro lado, é imperativa a superação da cidade como uma máquina de guerra e que, mesmo tendo de enfrentar de modo inédito certas relações, não deixemos de seguir considerando suas memórias e atributos fundamentais. É preciso aliar a essas novas posturas os valores elementares que compõem as nossas responsabilidades, de modo que superemos a fragmentação, a instabilidade e a fragilidade que prevalecem hoje.

O populismo requer uma certa franqueza e a intensificação da mensagem. Em muitas das novas práticas há um esforço para evitar a complexidade e a alienação que cobriram - talvez como uma cortina de fumaça - os discursos arquitetônicos do neoliberalismo. [...] O populismo se converteu na arma definitiva neste meio: só o mais óbvio e facilmente digerível sobrevive nesse ambiente. (Zaera-Polo, 2016, p.262)

No recente texto intitulado "Ya bien entrado el siglo XXI ¿Arquitecturas del Post-Capitalismo?”, Alejandro Zaera-Polo, arquiteto e crítico espanhol, nos fala de uma "simplificação" que acomete o cenário arquitetônico e que pretere uma das mais importantes constatações da segunda metade do século passado: a complexidade. Essa falta de rumos, a resposta passiva às condicionantes apresentadas e a fuga da complexidade nos colocam diante da produção consideravelmente rasa da arquitetura de nosso tempo. 
Diante da ausência das utopias modernas e das especulações pós-modernas, agora é necessário superar a vagueza contemporânea, rumo a uma construção complexa da arquitetura e consciente da dimensão humana que a acolhe. Que dos rastros ideológicos que a história nos lega, possamos preservar uma diversidade de princípios, sendo um deles o reconhecimento do mundo existente que não deve ser suplantado ou transformado por irrealidades que ignorem o valor de sua densidade humana. O respeito pelas pré-existências - materiais e imateriais - deve nos permitir enxergar a cidade de modo distinto, cauteloso e sensível. A cidade como uma união de lugares que convivem entre si e nos quais a arquitetura deve se fazer presente, como aponta o arquiteto, historiador e filósofo catalão Ignasi de Solà-Morales (2002, p.188):

A imaginação romântica que sobrevive em nossa sensibilidade contemporânea se nutre de memórias e de expectativas. Estrangeiros em nossa própria pátria, estranhos em nossa cidade, o habitante da metrópole sente os espaços não dominados pela arquitetura como um reflexo de sua própria insegurança, de seu vago deambular por espaços sem limites que, em sua posição fora do sistema urbano, de poder, de atividade, constituem uma expressão física de seu temor e insegurança e, ao mesmo tempo, uma expectativa do outro, do alternativo, do utópico, do porvir. ${ }^{4}$

Seja a arquitetura geradora do determinado ou do indeterminado, ela também é lugar. Estamos em lugares, vivemos em lugares, construímos nossas relações em lugares. Lugares que agora não devem mais ser criados a partir do marco zero da utopia ou da segregação, mas a partir de um sistema complexo de relações onde muitos agentes devem ser considerados e reconsiderados. Talvez, reconhecendo o valor simbólico da arquitetura, sua capacidade de construir essas situações e de promover o convívio, possamos tornar nosso cenário algo mais aprazível. Em suma, a arquitetura não pode ser uma ferramenta de segregação, mas sim de conciliação.

Assim, estamos diante de uma dimensão irrefutável de nossa atuação como arquitetos: contribuir para a construção da instituição humana do convívio e da compreensão. Uma situação onde a presença da arquitetura deve assumir sua responsabilidade própria e colaborar para a solidificação das instituições sociais, conforme defendido enfaticamente pelo arquiteto americano Louis I. Kahn: "O consenso humano é um senso de harmonia, de comunhão, de todos os sinos tocando em uníssono - não precisando ser entendido pelo exemplo, mas sentido como uma incontestável necessidade interior de uma presença. É uma inspiração com a promessa do possível"5 (apud McCarter, 2005, p.482).

\section{Incursão 3 (Presenças arquitetônicas)}

Diante disso, a retomada de algumas das diferentes presenças que a arquitetura propôs nas últimas décadas se faz necessária. Presenças que, para além da "arquitetura ou revolução" (Le Corbusier, 1998) que comandou a primeira metade do século XX, contam-nos hoje sobre as velozes mudanças que caracte- 
rizam nossos dias. Algumas dessas propostas nos renderam enganos, mas todas são contribuições fundamentais para entendermos a cidade e que deveríamos ver acumuladas numa extensão temporal muito mais dilatada.

Como em inúmeros outros campos, também no pensamento da arquitetura e do urbanismo as décadas de 1960 e 1970 foram prolíferas e, nas hegemonias pioneiras da Europa e dos Estados Unidos, vimos surgir grande parte das reflexões que responderam diretamente aos seus distintos contextos culturais, políticos e econômicos. Posturas que participam dessa complexidade urbana com a qual lidamos e que até hoje podem transitar da exaltação de uma cultura capitalista à uma austera resistência socialista.

O casal de arquitetos norte-americanos Denise Scott-Brown e Robert Venturi, em textos seminais como Complexidade e contradição na arquitetura (1966) (Venturi, 1995) e Aprendendo com Las Vegas (1972) (Venturi; Scott-Brown; Izenour, 2003), colocaram-nos diante do fato de que a arquitetura é comunicação. Revelando códigos de linguagens duramente neutralizados pela abstração radical alçada pelo racionalismo, demonstraram como ela é responsável por carregar mensagens, seja na maior escala urbana, seja na menor escala de uma construção. É desvelada aqui uma complexidade inerente à presença da arquitetura que não podia mais ser ignorada naquele momento, passando a ser tratada como um meio de identificação entre uma memória arquitetônica erudita e as exigências de uma cultura popular que florescia por todas as partes. Por outro lado, não podemos deixar de reconhecer que, com isso, também vimos apontada uma das maneiras mais extremas de como a arquitetura pode se comunicar e desenhar a cidade. Retrato da vigorosa sociedade de consumo americana, a eficiência de seu uso como propaganda levou a arquitetura a um esvaziamento substancial de significado, restando às suas superfícies e fachadas seus únicos e mais potentes instrumentos de presença e comunicação - o decorated shed ou "galpão decorado", como denominado por Venturi - fato que será levado a outros graus por arquitetos posteriores.

A essa visão, podemos contrapor a do arquiteto italiano Aldo Rossi que, numa crítica profunda ao funcionalismo vigente, trouxe à luz o fato de que as cidades não podiam ser definidas a partir de suas infraestruturas - dominadas pelos fluxos de mobilidade e tantos outros critérios funcionais -, mas sim pelos diversos outros fatos que a compõem, entre eles a sua própria história. Podemos identificar como uma das maiores contribuições de Rossi (1995) aquela sintetizada em A arquitetura da cidade (1966), no qual busca compreender as relações entre ambos segundo um sistema complexo de signos e códigos muito mais profundos do que sua mera imagem. É notável a diferença da postura de um arquiteto europeu que repugna a legitimação da cultura de consumo e, engajado noutra direção, busca a densidade histórica da arquitetura, seus códigos mais elementares e, principalmente, como essa pode construir cidades que realmente se evidenciem como resultado da coletividade humana. Aqui, a presença 
da arquitetura é muito mais do que a consequência de determinações funcionais e do incentivo a uma cultura capitalista. O compromisso do arquiteto reside na consciência de sua participação na construção de uma memória humana compartilhada, onde os valores que cada lugar por si só detêm - o "genius loci" devem ser fruto de um pensamento dotado de uma dimensão temporal que vá para muito além do efềmero.

$\mathrm{Na}$ Holanda, o arquiteto Herman Hertzberger, igualmente engajado na superação dos preceitos funcionalistas, supera os limites dessa contestação para também expor novas interpretações sobre o domínio público que, a seu ver, deveriam conduzir o desenho dos espaços arquitetônicos. Consolidado durante a década de 1970 em obras e textos - posteriormente reunidos no livro Lições da arquitetura (1991) -, o pensamento de Hertzberger (1999) se distanciava das preocupações de natureza formal de muitos arquitetos desse período. Concentrou-se em revelar o valor da pequena escala e de como as dimensões públicas e privadas das pessoas deveriam ser respeitadas para construirmos um estado social amplo. Independentemente de seu tamanho ou função, o edifício é pensando a partir de uma complexidade urbana e entendido como uma pequena cidade na qual uma associação de espaços equivalentes a ruas, praças e esquinas origina uma totalidade igualmente diversa e complexa. Junto a isso, encontramos uma presença arquitetônica participativa, onde somente a partir da apropriação de seus usuários é que realmente pode se completar.

Junto a esses nomes da arquitetura, dois pensadores de fora da categoria foram igualmente fundamentais: a economista e jornalista norte-americana Jane Jacobs (2000), consagrada por seu ensaio Morte e vida de grandes cidades (1961) e o sociólogo francês Henri Lefebvre (2001), reconhecido por seu livro $O$ direito à cidade (1968). Dentro de suas especificidades, ambos compartilharam a tentativa de conscientizar arquitetos e urbanistas sobre a emergência de superarem os dogmas racionalistas e funcionalistas que vinham configurando as cidades e tornando-as substancialmente desumanas. Com isso, a rua, o pedestre, o lugar, a valorização da vida cotidiana, o respeito à heterogeneidade de suas estruturas e à diversidade de seus indivíduos foram mensagens fundamentais para presenças mais humanizadas dos espaços urbanos.

Essas referências são apenas parte de um conjunto muito maior que segue apresentando novos rumos para a nossa atuação nas cidades. Todos aqui foram muito além dos limites da ação e participaram intensamente do campo da reflexão teórica - atividades que vemos muitas vezes desvinculadas. Sem pensamento não há ação e, em períodos de névoas, lembrar as lições de pensadores como esses pode ser de grande contribuição, ainda mais quando seguimos presenciando nossas cidades sendo construídas por agentes - entre eles os arquitetos - que ignoram consideravelmente o valor da memória.

\section{Incursão 4 (Especulações contemporâneas)}

Para falar sobre o arquiteto mais influente das últimas décadas no que se 
refere à compreensão da cidade contemporânea, o holandês Rem Koolhaas, é conveniente iniciarmos com suas próprias palavras:

Como tudo na Cidade Genérica, a sua arquitetura é o resistente feito maleável, uma epidemia do desempenho não mais através da aplicação de um princípio, mas através da aplicação sistemática do que não tem princípio. ${ }^{6}$ (Koolhaas, 1995, p.1261)

O espaço-lixo é político: ele depende da eliminação central da capacidade crítica em nome do conforto e do prazer. ${ }^{7}$ (Chung et al., 2001, p.415)

[...] A Grandeza já não faz parte de nenhum tecido urbano. Ela existe; no máximo, coexiste. Seu subtexto é dane-se o contexto. ${ }^{8}$ (Koolhaas, 1995, p.502)

Através da contaminação em vez da pureza e da quantidade em vez da qualidade, somente a Grandeza pode genuinamente sustentar novas relações entre entidades funcionais que expandem suas identidades ao invés de limitá-las. ${ }^{9}$ (Koolhaas, 1995, p.511)

Devidamente por seu tamanho, esses edifícios entram num domínio amoral, para além do bem e do mal. Seu impacto independe de sua qualidade. ${ }^{10}$ (Koolhaas, 1995, p.501)

Realizadas em textos-manifestos como Nova York delirante (1978) (Koolhaas, 2008) ou $S, M, L, X L$ (Koolhaas; Mau, 1995), as afirmações de Koolhaas são categóricas e postulares. Fazem-nos oscilar entre sua lucidez excepcional sobre a realidade e seu caráter camaleônico de extrair oportunidades de quaisquer circunstâncias. $\mathrm{O}$ grau de clareza e contundência de suas ideias fizeram - e ainda fazem - que muitos as seguissem de modo doutrinado e confuso, encantados por uma suposta realidade livre de critérios. A cidade genérica, o espaço-lixo, a banalização do contexto, a potência da pura grandeza, a amoralidade arquitetônica, são leituras precisas e reveladoras de como todos os valores fundamentais acima ressaltados foram rapidamente aniquilados pelas transformações das últimas décadas. Assim, é preciso dizer que as constatações de Koolhaas nos colocam diante de condições extremas e que deveriam ser sumariamente enfrentadas, reivindicando uma transformação decisiva do violento predomínio do capital, do corporativismo, do consumo, da imagem e de muitos outros parâmetros que passaram a dominar as estruturas urbanas das metrópoles globais. No entanto, é perturbadora a passividade com que muitos passaram a se posicionar frente a elas, inclusive com a pretensão ilusória de alcançarem algum sentido válido por meio de sua própria manutenção. A profundidade da obra escrita e construída de Rem Koolhaas - concebida em seus escritórios OMA e AMO - é de excepcional contribuição e ainda irá reverberar por muito tempo nas discussões sobre arquitetura e cidade. Porém, merece ser cuidadosamente interpretada. Não é possível imaginar que possamos extrair qualquer coisa digna de uma amoralidade ou de um contexto onde princípios não são mais imprescindíveis. Estamos diante do fato de que forças e interesses privados suplantaram sumariamente qualquer dimensão pública de nossos meios, sejam como instrumentos de po- 
der ou como ferramentas de proliferação de lucros. A liberdade que buscamos, e que em seu pensamento também é ressaltada, deve ser cultivada e exercida de modo preciso, segundo uma indispensável consciência ética e pública.

Também por meio de sua obra escrita ${ }^{11}$ e construída o arquiteto franco-suíço Bernard Tschumi foi responsável por uma das contribuições mais relevantes dos últimos tempos. Partindo de uma mesma consciência sobre a conjuntura conflituosa de nossas cidades e alinhando critérios que dizem respeito tanto ao urbanismo como à arquitetura - inclusive por entendê-los com uma coisa só -, colocou-nos diante de uma ideia onde o território urbano não deveria se limitar às disputas, mas também se abrir a outras relações de convergências e divergências registradas nos textos de Architecture and Disjunction (Tschumi, 1996). Tschumi defende que o programa - ou função - como origem da arquitetura deve ser suplantado pela imprevisibilidade do espaço não programado: arquitetura sendo cidade e permitindo que a apropriação espontânea de seus espaços por parte das pessoas seja sua característica mais valiosa. A seu ver, é a partir disso que a arquitetura de fato acontece: com a presença e a participação efetiva das pessoas para a construção de seus próprios sentidos. Aquilo que denomina "evento" e que conduzirá suas concepções é, de fato, uma compreensão importante de como a arquitetura deve se abrir para a cidade e respeitar as reivindicações de seus habitantes. Mais do que definir e controlar, a arquitetura deve permitir o surgimento do indeterminado e de possibilidades fundamentalmente urbanas que se consumam e transformam com o tempo a partir de suas dinâmicas sociais, políticas e culturais irrefreáveis:

"Programa" deve ser distinguido de "Evento". Um programa é um conjunto determinado de ocorrências esperadas, uma lista de funções necessárias, muitas vezes baseadas no comportamento social, hábito ou costume. Em contraste, os eventos ocorrem como um conjunto indeterminado de resultados inesperados. Revelam potencialidades escondidas ou contradições em um programa, relacionando-os com uma configuração espacial particularmente apropriada (ou possivelmente excepcional), podem criar condições para a ocorrência de eventos inesperados. Por exemplo, pode-se combinar ou criar atividades programadas para que elas cobrem uma configuração espacial, de tal forma que, através da mistura de itens programáticos comuns ou previsíveis, gerem eventos incomuns ou imprevisíveis. Muitas vezes tenho chamado essa configuração particular do espaço de "entre". (Tschumi, 2000, p.13)

Junto às ideias aqui destacadas como seminais para seguirmos pensando a arquitetura, podemos dizer que esse "entre" - presente em tantas outras abordagens científicas e filosóficas - é uma conquista do final do último século. Ao alcançar a arquitetura, ajudou-nos a reconhecer a sociedade complexa e dinâmica da qual somos parte e, pincipalmente enxergar outras relações que sua presença pode e deve considerar na atualidade. De certo modo, essa conquista implica a consideração da alteridade como aspecto indissociável dos pensamen- 
tos urbano e arquitetônico, e na espera de que se contagiem cada vez mais pela consciência pública de sua presença, pelo impacto temporal de sua permanência, pelo acolhimento da diversidade e pela consideração do outro como parte e destino de suas ações.

\section{Pausa (Diante da cidade fraturada)}

Mas que arquiteturas constroem a cidade de hoje? Como a presença dos espaços edificados promove a vida urbana - pública e privada? Fácil identificar o quão intimidador são essas presenças e como nos colocam diante da quimera de uma cidade formada por inúmeras cidades, cada uma isolada em si mesma.

O Centro, não há uma pessoa que não o reconheça com assombro, é realmente grande. (Saramago, 2000, p.101)

Ele é sempre interior, tão extenso que raramente você percebe seus limites; ele promove a desorientação de todos os jeitos [...]. ${ }^{12}$ (Chung et al., 2001, p.408)

Como qualquer outra metrópole global, São Paulo também está repleta de assombrosos "Centros" como o que descreve o escritor português José Saramago no livro A caverna (2000) e cuja fantasia literária encontra seu espelhamento direto na realidade concreta das palavras de Koolhaas. Ambos falam de uma dimensão interior avassaladora presente nas cidades que há muito vem evidenciando a anulação de uma dimensão exterior de relações, retrato cabal do predomínio do privado sobre o público.

É a "cidade-território" descrita pelo filósofo italiano Massimo Cacciari que nos mostra também como esta fragmentação territorial subtrai os nossos referenciais comuns e, por conseguinte, qualquer compreensão de unidade e conjunto: "Estamos, agora, na presença de um espaço indefinido, homogêneo, indiferente nos seus lugares, onde se dão acontecimentos que se baseiam em lógicas que já não correspondem a um desígnio unitário de conjunto" (Cacciari, 2010 , p.33) Já não temos ideia de onde estamos inseridos, e isso, como instrumento de controle, é de uma eficiência fatal.

Isolamo-nos dentro de centros residenciais, comerciais, culturais, entre outros: ilhas - ou bolhas - de segregação radical. É esse um dos principais sintomas de nosso tempo: a condição fraturada do contexto a partir de critérios econômicos que acabam gerando mundos dentro de mundos, organizados segundo posições sociais e uma ilusória liberdade de ir e vir.

Isolamo-nos também nas dimensões colossais que nossa cidade alcança: essa expansão territorial que exige deslocamentos gigantescos é responsável pelo comprometimento da qualidade de vida da população que a enfrenta dentro das precárias infraestruturas públicas e privadas de mobilidade.

Isolamo-nos, por fim, na especulação e na informalidade provocadas pelo uso predatório do solo urbano: enquanto uma parcela majoritária da população se concentra em periferias precárias e desprovidas de condições mínimas de habi- 
tabilidade e urbanidade, tanto as políticas públicas como as especulações imobiliárias abstêm-se da efetiva construção do ambiente urbano, prevalecendo sobre as oportunidades democráticas disponíveis na cidade. Como aponta Cacciari (2010, p.55): “O desenvolvimento da cidade de metrópole para território não pode, portanto, ser programado: é este o drama de todos os arquitetos e urbanistas. A dificuldade não depende da incapacidade deles ou da vontade política dos administradores, depende da impossibilidade de programar".

Eis o território de disputa do urbanismo contemporâneo, condição em que a arquitetura - reinventando-se numa diversidade de atuações complementares - continua devendo existir. Assim, é necessário compreender as dualidades instauradas por esse território de extremos: a memória e o desejo, a ordem e o caos, o convívio e a intimidade, e olhar a cidade como uma paisagem a ser desvelada. Como aponta o filósofo brasileiro Nelson Brissac Peixoto (2004, p.177):

Olhar um objeto é mergulhar nele. Os objetos circundantes tornam-se horizonte, a visão é um ato de dois lados. Ou seja: ver um objeto é ir habitá-lo e daí observar todas as coisas. Mas, como também nelas estou virtualmente situado, tomo de diferentes ângulos o objeto principal de minha observação. O olhar se faz nas duas direções, cada objeto é espelho de todos os demais.

Precisamos cada vez mais que o lugar da arquitetura se misture com o lugar da cidade e que um seja visto como o espelho do outro. As circunstâncias de hoje demandam que se reconheça a potência da arquitetura e do urbanismo nas mais variadas escalas e instâncias: seja no planejamento distante, seja no desenho do hoje, o encontro de ambos não pode resultar em outra coisa que não o diálogo, o seu mais fundamental fato urbano.

\section{Diálogos questionadores}

Se passamos a entender a construção da arquitetura como a de diálogo (com a cidade), penso que poderíamos sempre iniciá-lo com algumas perguntas fundamentais:

O que a cidade nos apresenta? (Chamemos de lugar, contexto ou pré-existência, é necessário considerar a cidade sempre como algo presente e sobre o qual atuar respeitando as dimensões sociais, políticas, econômicas e culturais de seus habitantes, além de tudo aquilo que define seu ambiente construído.)

$\mathrm{O}$ que interpretamos da cidade? (É preciso compreender que pensar a arquitetura é exercer uma capacidade interpretativa que, precisamente por seu grau de responsabilidade e impacto, deve estar profundamente embasada. Há um conteúdo científico a ser consolidado e posteriormente contagiado pelo subjetivismo que for preciso. Logo, pensar a arquitetura é um processo que se inicia muito antes de se fazer arquitetura.)

O que oferecemos para a cidade? (A ação de um arquiteto é uma hipótese dentre tantas outras que podem ser construídas a partir das interpretações oferecidas por diferentes valores. No entanto, no cenário complexo de condições 
e agentes que definem a cidade, é impossível imaginar qualquer "solução" ou "resposta" absoluta que, solitária e imutavelmente, seria capaz de contemplar toda sua complexidade.)

O que se compreende de nossas ações? (Arquitetura é linguagem e comunicação, fato que traz consigo um campo aberto e imprevisível de acolhimento de nossos objetivos. É preciso cultivar essa amplitude e permitir que a compreensão daquilo que propomos não seja unilateral, mas que reflita a liberdade inerente à cidade e acolhedora daquilo que não prevemos.)

Por fim, é necessário dizer que a nossa consciência ética é basal para cada uma dessas perguntas e que, como aponta Solà-Morales (2002, p.189): "O desamparo do sujeito, a perda de consistência dos princípios tem uma correspondência ética e estética". ${ }^{13}$ Falamos de uma única coisa: arquitetura e cidade. Assim como a arquitetura não acontece por si só, a cidade precisa da arquitetura para acontecer, num processo de influência e interdependência mútua que demanda a cautela de nossas reflexões para qualquer um de nossos atos.

\section{Diálogos categóricos}

Assim, volto aqui às reflexões de Louis I. Kahn sobre como entende o fazer da arquitetura e da cidade que, a meu ver, poderiam ser tratadas como “imperativos categóricos" (Kant, 2016) muito precisos para o nosso tempo.

O primeiro fala sobre compreender as coisas que nos cercam como instituições caracterizadas por valores e fundamentos próprios que devem ser respeitados e dignificados: "Uma cidade é medida pelo caráter de suas instituições. A rua é uma de suas primeiras instituições" ${ }^{14}$ (McCarter, 2005, p.483).

O segundo nos esclarece que o juízo sobre essas instituições é que deve conduzir nosso pensamento sobre a cidade e, se a rua é uma delas, a arquitetura também é: "As instituições das cidades podem se engrandecer graças ao poder de seus espaços arquitetônicos"15 (McCarter, 2005, p.470).

O terceiro nos coloca diante da relação entre essas duas instituições, a arquitetura e a rua, sobre as quais Kahn afirma: "A arquitetura é a construção de um ambiente; um conjunto de ambientes. A luz é a luz daquele ambiente. Os pensamentos trocados entre alguéns não são os mesmos em um ambiente como são em outro. Uma rua é um ambiente; um ambiente comunitário por consenso"16 (apud McCarter, 2005, p.478). Temos aqui o imaginário da cidade como uma casa onde cada espaço tem suas próprias características e que possam ser apropriados de maneiras igualmente singulares. Dependemos dessa qualidade para uma boa vida e uma boa convivência.

O quarto fala sobre a compreensão da cidade como uma decisão humana um consenso ou acordo universal - de vivermos e convivermos conjuntamente: "Quão inspirador seria o tempo em que o senso de acordo humano fosse sentido como a foça que traz novas imagens" ${ }^{17}$ (McCarter, 2005, p.482). Ilustradas por meio do valor da rua, temos aqui a dimensão pública que devemos encontrar em qualquer espaço e que estimule a criações cada vez mais correspondentes a ela. 
A ética por trás da postura de Kahn talvez não seja absoluta, mas deve ser revisitada pelo valor humanista que carrega e, principalmente, por revelar de modo sensível que não podemos tratar nosso ambiente de vida, a cidade, como um campo de batalha, mas sim como um lugar de encontro e convivência. É necessário buscar novos acordos.

\section{Diálogos abertos}

Diante disso, proponho a abertura de alguns apontamentos sobre princípios e fundamentos que, numa época em que nevoeiros (Wisnik, 2012) ocultam os rumos para onde seguir, venham nos ajudar a construir esses acordos. As dualidades aparecem aqui não como um enfrentamento de opostos, mas como um encontro de singularidades que podem originar relações mais completas e respeitosas entre o que nos cerca.

Sobre os lugares e as frestas: devemos ser conscientes de que a arquitetura atua sempre sobre algo que já existe, e reconhecermos nas pré-existências materiais e imateriais suas razões fundantes. É o respeito à ideia de lugar que permite a construção de identidades, não apenas arquitetônicas, mas principalmente daqueles que as vivenciam. Logo, é primordial não esquecermos que cada um desses lugares possui uma identidade própria que deve ser respeitada por nossas ideias. Junto a isso, o olhar contemporâneo nos permite mirar para além dos lugares que estão diante de nós, alcançando aqueles que descobrimos a partir de um reconhecimento mais pleno das camadas que constituem nossas cidades. São essas frestas - lugares ocultos e subestimados - que devem também formar parte de nossas preocupações, podendo nos colocar diante de outras hipóteses de relações entre arquitetura e cidade.

Sobre a presença e o singular: toda existência implica uma presença perante aquilo que está fora dela. Isso é a arquitetura na cidade e, seja qual for a sua natureza, o simples fato de se fazer presente deve implicar imediatamente a consciência do que é e do que será para quem a vivenciar. É necessário lembrar que a mais simples presença pode atingir uma potência descomunal. Logo, se essas presenças se dão em lugares e condições únicas, elas mesmas também devem ser compreendidas como fatos singulares: cada presença arquitetônica é única e é essa especificidade que sintetiza a criação complexa e cautelosa que pode torná-la também um lugar.

Sobre o caráter e a ética: toda realização arquitetônica possui um caráter próprio e esse é diretamente emanado sobre as pessoas e a cidade. Seus valores estéticos podem ser latentes, mas ela é, acima de tudo, um registro contundente dos valores éticos que a geraram. Assim, nossos critérios e juízos devem estar embasados sobre um posicionamento respeitoso, crítico e íntegro em cada momento que pensamos arquitetura.

Sobre o pequeno e o grande: a contribuição da arquitetura independe de sua escala. É preciso que a pretensão do grande seja superada e entendermos que, muitas vezes, é nas menores ações que residem as dimensões sensíveis e 
acolhedoras que devem compor a cidade. Do planejamento urbano da macroescala ao desenho urbano da microescala, devemos reconhecer valores distintos e complementares, ambos cruciais para a configuração de uma urbanidade plena.

Sobre o formal e o informal: participam hoje da construção das cidades não apenas as instituições consolidadas, mas também outras ainda num processo de reconhecimento. O que presenciamos cada vez mais é uma dimensão social urbana tomando parte naquilo que é seu, e a cidade deve respeitá-la. A arquitetura não se pensa ou faz sozinha. É primordial entendê-la cada vez mais como um processo coletivo de diálogo aberto e em contínuo desenvolvimento, no qual, precisamente a partir do encontro, poderá potencializar as individualidades e especificidades imbricadas em cada uma de suas partes.

Sobre a expressão e a linguagem: não há forma que valha mais por ela mesma do que pela mensagem que carrega. Percorrido um século de tantas interpretações sobre esse caráter da arquitetura, um fato persiste: sua comunicabilidade deve ser respeitada. É necessário superar a mudez da arquitetura e a leviandade do seu consumo como imagem. Se entendemos que sua presença é o registro de valores, é imperativo que a tradução desse conteúdo em linguagem ocorra de modo profundo e condizente com a densidade daquilo que está ali refletido.

Sobre a poesia e o significado: nossa condição urbana continua sendo afetada pelo peso de suas inconsistências - seja a desigualdade, a intolerância ou a precariedade. Se a arquitetura é muda, a cidade também o é. Assim, mais do que nunca, é necessário possibilitar a construção de sentidos, contribuirmos para que as mensagens expressadas pela arquitetura sejam plenas de poéticas (Margotto, 2016) e que permitam cada contar a sua própria história. Essa é a beleza da criação e a cidade a requer, não através de ações de caráter combativo, mas sim de atos criativos estimulados por um olhar sensível sobre o mundo.

Sobre o cheio e o vazio: é necessário proteger a cidade da saturação total de seus espaços. A força predatória das especulações de seu solo e o recurso excessivo da densidade como alternativa para minimizar suas deficiências vem fazendo que nos encontremos envolvidos por ambientes de uma compressão sem igual. Tanto quanto o cheio - abrigo de grande parte de nossas atividades -, o vazio é igualmente importante. Além de também acolherem parte da pulsação urbana, é assim que as fundamentais pausas e intervalos podem acontecer. Bem como o olho precisa do horizonte, a cidade precisa do vazio.

Sobre o dentro e o fora: independentemente de qual, encontrar-se em um desses estados pode ser considerado uma condição de isolamento. Isolamento que pode ser voluntário e protetivo, mas que também pode refletir uma segregação real ou ilusória. É preciso entender o que é exterior e interior na arquitetura como espelhos das condições públicas e privadas que estruturam nossas cidades. Assim, é necessário que esses limites sejam pensados segundo o compromisso primário da arquitetura com a dimensão pública de sua presença. A vida social depende das linhas tênues de transição entre o público e o privado, o coletivo e o individual. 
Sobre o tempo e a memória: se olharmos para a dimensão temporal do que é realizado hoje, presenciaremos a soberania da velocidade de um tempo raso e fugaz. Um tempo do qual foi retirado seu próprio tempo. No entanto, as coisas duram e, aliás, devem durar. Não me refiro a uma medida exata, mas à imprescindível consciência temporal daquilo que fazemos. Os esforços desprendidos para a construção de nosso ambiente são grandes demais para serem anulados num instante ou para não terem o mínimo de consistência. Se não tivermos memória, eis que estaremos de fato perdidos numa sobreposição e anulação de tempos ignorantes. Para isso, temos que ter o que contar. Temos que ter lugares, sentidos, significados, não para a preservação de algo atemporal, mas para dialogarmos de modo mais profundo com esse movimento contínuo e sem fim.

\section{O berço do humano}

As cidades, como os sonhos, são construídas por desejos e medos, ainda que o fio condutor de seu discurso seja secreto, que as suas regras sejam absurdas, as suas perspectivas enganosas, e que todas as coisas escondam uma outra coisa. (Calvino, 1990, p.44)

$\mathrm{O}$ que pensar disso tudo que demanda de nós muito mais do que um objetivismo? Eis que dimensões espaciais e temporais nos conduzem: "Ordem e desejo de eternidade são as matérias-primas de nossos pensamentos, seria impossível pensar fora deste universo" (Vigliecca, 2014, p.41) e essa compreensão é primordial para um pleno domínio do ofício e das responsabilidades do arquiteto.

Hector Vigliecca - arquiteto uruguaio e naturalizado brasileiro - lembra-nos de como a cidade não deve ser encarada como uma fatalidade, mas como uma realidade. Não como uma infraestrutura, mas como um lugar. Seu pensamento e obra (Vigliecca, 2012, 2014) são um respiro num Brasil que ainda a enxerga como uma construção infraestrutural, bem como, às vezes, a própria arquitetura. Sua produção - uma das mais contundentes das últimas décadas - evidencia como aquela cidade entendida como um campo abstrato onde repousam objetos isolados ainda precisa ser superada. Ao contrário, a cidade é uma hipótese viva onde a arquitetura deve manter a sua pulsação num âmbito democrático de relações.

Portanto, devemos assumir categoricamente o que representa esse ofício, defendendo os direitos da arquitetura e do urbanismo, mas também os seus deveres, que vão muito além da construção de uma habitabilidade mínima. Nosso compromisso deve ser o da construção de um hábitat humano onde arquitetura e cidade se influenciam mutuamente por meio de um diálogo sensível. É preciso que nos deixemos contagiar pelo mundo - por todas as diferenças nele presentes - e termos em conta que, dentro da liberdade que temos de atuar, as consequências de cada um de nossos atos dizem respeito a todos.

Então, por que nos engajarmos em incursões tão árduas? 
Esta lealdade à consciência da minha formação resiste a transpor a barreira das utopias do projeto cultural e social moderno sobre a ideia e forma dos convívios do público com o coletivo e com o privado, concatenados numa comunhão harmônica. Só podemos concluir nostalgicamente que nossos projetos são uma ilusão. (Vigliecca, 2014, p.41)

É por meio dessa aliança entre a consciência de nossas experiências e a lealdade aos princípios que todos devemos ter que podemos preservar a potência de nossos anseios e deveres. É preciso seguir alimentando o desejo inabalável de construirmos esse encontro público e respeitoso, seja o da hospitalidade de Odisseu e seu pai, seja o da comunhão pública de todos os nós.

Do silêncio de seus corpos construídos, do eco de seus espaços, a arquitetura pulsa com a cidade e é de ambas que emana grande parte do cenário da vida. Se o que impera em nossos dias é a inconsistência do que existe, que da consistência dos sonhos possa emergir o futuro, uma superarquitetura pela libertação e construção do berço do humano.

\section{Notas}

1 Ver World Urbanization Prospects: The 2014 Revision / United Nations, Department of Economics and Social Affairs, Population Division, 2015.

2 Todas as citações de referências bibliográficas em língua estrangeira são de tradução livre do autor.

3 Fragmento do texto "Paradigmas fin de siglo (fragmentación y compacidad en la arquitectura reciente)" de 1998.

4 Fragmento do texto "Terrain vague" de 1995.

5 Fragmento do texto "The Room, the Street and Human Agreement" de 1971.

6 Fragmento do texto "The Generic City" de 1994.

7 Fragmento do texto "Junkspace" de 2001.

8 Fragmento do texto "Bigness, or the problem of the large" de 1994.

9 Ibidem.

10 Ibidem.

11 Ver textos Arquitetura e limites I, II e III (1980-81) em Nesbitt (2006).

12 Ibidem, p.15.

13 Ibidem, p.5.

14 Ibidem, p.6.

15 Fragmento do texto "Form and Design" de 1960-61.

16 Texto extraído de desenho de Louis I. Kahn.

17 Ibidem, p.6.

Referências

CACCIARI, M. A cidade. Trad. José Serra. Barcelona: Gustavo Gili, 2010. 
CALDEIRA, T. P. do R. Cidade de muros: crime, segregação e cidadania em São Paulo. São Paulo: Ed. 34; Edusp, 2000.

CALVINO, I. As cidades invisíveis. Trad. Diogo Mainardi. São Paulo: Cia. das Letras, 1990. CHUNG, C. J.; INABA, J.; KOOLHAAS, R.; LEONG. S. T. Harvard Design School Guide to Shopping. Colonia: Taschen, 2001.

HERTZBERGER, H. Lições de arquitetura. São Paulo: Martins Fontes, 1999.

HOMERO. Odisseia. Trad. Christian Werner. São Paulo: Cosac Naify, 2014.

JACOBS, J. Morte e vida de grandes cidades. São Paulo: Martins Fontes, 2000.

KANT, I. Crítica da razão prática. São Paulo: Martins Fontes, 2016.

KOOLHAAS, R. Nova York delirante. São Paulo: Cosac Naify, 2008.

KOOLHAAS, R.; MAU, B. S, M, L, XL. New York: Monacelli Press, 1995.

LE CORBUSIER, Por uma arquitetura. São Paulo: Perspectiva, 1998.

LEFEBVRE, H. O diveito à cidade. São Paulo: Centauro, 2001.

MARGOTTO, L. Lições da arquitetura: leituras a partir de poéticas. 2016. Tese (Doutorado em Arquitetura e Urbanismo) - Faculdade de Arquitetura e Urbanismo, Universidade de São Paulo. São Paulo, 2016.

MCCARTER, R. Lowis I. Kahn. London: Phaidon, 2005.

MONEO, R. El Croquis. Antología de Urgencia: 1967-2004. Madrid: El Croquis Editorial, 2004.

. Remarks on 21 works. London: Thames \& Hudson, 2010.

NESBITT, K. (Org.) Uma nova agenda para arquitetura: antologia teórica 19651995. São Paulo: Cosac Naify, 2006.

PEIXOTO, N. B. Paisagens urbanas. São Paulo: Senac, 2004.

ROSSI, A. A arquitetura da cidade. São Paulo: Martins Fontes, 1995.

SARAMAgO, J. A caverna. São Paulo: Cia. das Letras, 2000.

SOLÁ-MORALES. I. Territorios. Barcelona: Gustavo Gili, 2002.

TSCHUMI, B. Architecture and Disjunction. Cambridge: MIT Press, 1996.

. Event-Cities 2. Cambridge: MIT Press, 2000.

VENTURI, R. Complexidade e contradição na arquitetura. São Paulo: Martins Fontes, 1995.

VENTURI, R.; SCOTT-BROWN, D.; IZENOUR, S. Aprendendo com Las Vegas. São Paulo: Cosac Naify, 2003.

VIGLIECCA, H. Hipóteses do real: concursos de arquitetura e urbanismo 1971-2011. São Paulo: Arquiteto Héctor Vigliecca e Associados, 2012.

. O terceiro território: habitação coletiva e cidade. São Paulo: Arquiteto Héctor

Vigliecca e Associados, 2014.

WISNIK, G. Dentro do nevoeiro: diálogos cruzados entre arte e arquitetura contemporânea. 2012. Tese (Doutorado em Arquitetura e Urbanismo) - Faculdade de Arquitetura e Urbanismo, Universidade de São Paulo. São Paulo, 2012. 
ZAERA-POLO, A. Ya bien entrado el Siglo XXI ¿Las arquitecturas del Post-Capitalismo? In: El Croquis 187. Madrid: El Croquis Editorial, 2016.

RESUMO - Este texto busca refletir sobre as relações entre o pensamento da arquitetura e a cidade contemporânea, permeando trajetórias históricas e como os contextos político, econômico, social e cultural devem ser considerados em qualquer processo que lide com a complexidade da condição urbana que nos cerca.

PALAVRAS-CHAVE: Arquitetura, Cidade, Espaço, Estratégia, Linguagem, Metrópole, Paisagem, Processo criativo, Território, Urbanismo.

ABSTRACT - By permeating historical trajectories, this text seeks to discuss the relations between architectural thought and the contemporary city, and how the political, economic, social and cultural contexts must be considered in any process that deals with the complexity of the urban condition that surrounds us.

KEYWORDS: Architecture, City, Creative process, Language, Landscape, Metropolis, Space, Strategy, Territory, Urbanism.

Daniel Corsi é graduado em Arquitetura e Urbanismo pela Faculdade de Arquitetura e Urbanismo da Universidade Mackenzie (2003). Mestre em Arquitetura e Urbanismo pela Faculdade de Arquitetura e Urbanismo da Universidade de São Paulo (2012). Professor na FAU-Mackenzie e Escola da Cidade. Sócio fundador do escritório Corsi Hirano Arquitetos. @-corsi@corsihirano.com

Recebido em 19.9.2017 e aceito em 12.10.2017.

I Faculdade de Arquitetura e Urbanismo, Universidade Presbiteriana Mackenzie, São Paulo, São Paulo, Brasil. 